\title{
The Role of Social Capital (Tribe or Civil Society Organizations) in Achieving Sustainable Development in the City of Amman
}

\author{
Abeer Ali Al-Salahat \\ PHD student of Sociology. Lecturer, Faculty of Art and Sciences, Applied Sciences Private University, Amman, \\ Jordan
}

\begin{abstract}
This study dealt with the concept of social capital, through a network of social relations and the role played to achieve economic and political needs of the study Examples of aspects of social capital, such as clans and civil society organizations, were presented, and how sustainable development can be achieved through activating the role of social capital in Amman. The researcher followed the descriptive and analytical approach in reviewing and analyzing a set of previous studies based on Bourdieu and Putnam's description of social capital. The results of the study were summarized in the importance of activating the role of social capital in achieving sustainable development by relying on its various manifestations in the city of Amman, whether the clan or civil society organizations, because of their negatives and positives for the Jordanian society, and dealing with the components of society with respect for its privacy to achieve better results for sustainable development.
\end{abstract}

DOI: $10.7176 / \mathrm{JEP} / 11-28-05$

Publication date:October $31^{\text {st }} 2020$

\section{Introduction}

The concept of capital began with the German theorist Karl Marx, who focused on ownership of the means of production, as an important element of controlling societies, and this concept of capital developed to cover non-monetary dimensions represented by cultural, religious and social capital.

Social thinkers (Pierre Bourdieu, Robert Putnam, and James Coleman), who laid the foundations for it, are credited with the development of the concept of capital social capital, in addition to setting standards and determinants for measuring social capital, its importance to the individual within the group, and how it achieves its goals And many advantages at the economic, political and social levels (Abu Zahir, 2008).

This study comes to address the role of social capital represented by the network of social relations in achieving sustainable development goals. Bourdieu defines social capital as "the resources that individuals possess, whether quantitative or qualitative, that can be used in a strategic way to obtain advantages, and which represents a force that helps establish social advantages for the two social actors" (Turner, 2006).

Sustainable development is a way to improve the economic and living standards without wasting wealth, while preserving a healthy environment for future generations to enjoy. This sustainable human development cannot be achieved without the presence of productive and creative social capital. Activating the role of social capital leaves a positive economic impact on income earners. The low level in the society without leaving a negative impact on the high income earners, through the integration between them, and this leaves a positive economic return on the entire society, although they are activities far from the market (Ahmed Zayed et al).

\section{Problem of the Study:}

The study deals with the development of the concept of social capital as a result of changing and developing forms of social relations in various societies, through the succession of economic, political and intellectual trends, and this indicates that the importance of the social network and its impact on societies despite the great social change that we see its effects on the social structure globally and locally.

This research is concerned after getting acquainted with the concept of social capital and its manifestations in the Jordanian society, especially the city of Amman, which is a high population density and enjoys modern urban features. The city of Amman.

Accordingly, the problem of the study lies in answering the following main question:

To what extent is there a role for social capital in achieving sustainable development in Amman?

\section{Importance of the Study:}

The importance of the study is that it is one of the first studies to shed light on the role of social capital (represented by clans and civil society organizations) in achieving sustainable development in the city of Amman, especially with the emergence of new and modern forms of social capital in light of the tremendous technological development and progress in the current era.

Objectives of the study

This study aims to identify: 
The concept of social capital

Aspects of social capital in Jordan (tribes and civil society organizations)

The role of social capital in achieving sustainable development

- How to activate the role of social capital in achieving sustainable development to make the most of it.

\section{Procedural definitions}

Role: It is meant by studying how to benefit from the social network in achieving sustainable development goals. Social capital: the network of social relationships that gives individuals political and economic advantages

The clan: a group of people who are related by blood or lineage

Civil society organizations: they are non-governmental and non-profit organizations created by a group of people to support a cause, or to express values and principles.

Sustainable development: it is continuous development that does not stop at a certain limit, but is renewed, so that the current generation benefits from it, and that does not prevent future generations from benefiting from it.

The city of Amman: is the capital of the Hashemite Kingdom of Jordan, and its largest city is numerous, and it is the administrative and commercial center of the state, and its population in 2020 is approximately 4 million people.

Previous studies and theoretical framework:

Many previous studies have dealt with the concept of social capital, in various Arab and Western societies, and it has been linked to many concepts, explaining its relationship to many demographic variables, and the extent of its impact on most groups and segments of society, and among these studies that dealt with the concept of social capital:

TANG1 LIVING TANG (2018)

In China, this study deals with the relationship between social capital and group behavior through social capital theory to explain and analyze the causes of group behavior in traditional society. However, the uniqueness of group behaviors in a network scenario determines that the effects of social capital on network group behavior differ from those on actual group behavior to some extent. Therefore, systematic explanations are necessary to explore how network group behavior works at the level of social capital. To explore the factors affecting network group behavior and thus obtain corresponding solutions, the study constructed a hypothesis model for the spirit of social capital for the behavior of the virtual community network group on the basis of social capital theory. The relationship between social capital, sense of virtual community, and network group behavior was verified by the structural equation model using survey data for 408 active users from three popular virtual communities of the type of interest (Tianya Community, Mob Society, and Baidu Tiba) obtained from March 2017 to April 2017. Results show that social capital not only directly affects network group behavior however

Also indirectly in the influence of network group behavior through the mediation of a sense of virtual community. Members of virtual community groups with high social capital actively participate in group behaviors. The improvement of group members regarding participation in group behaviors is mainly due to mutual trust, commitment and interaction among the group members. The participation of group members in group behaviors is further enhanced through a perceived sense of membership, inclusion, and effectiveness. Therefore, the influencing mechanism of social capital and sense of hypothetical community on network group behavior is revealed to some extent. The conclusions presented in this study provide interventions for virtual community managers who aim to enhance the internal management of the virtual community in order to encourage positive behavior of group networks for further improvement in electronic organizational effectiveness.

2- Belhanafi, Amina (2017)

This research deals with the concept of social capital and what it is related to in terms of sources and determinants, the exclusive formation and measurement of social capital despite the multiplicity of its concepts and interpretations. And groups within society, and thus social capital may be: social cohesion, formal and informal organizations' good neighborliness, friendship, family relations, and other criteria that prevent society from collapsing, which is what is necessary for social relations and bonds that bring people together and groups. As for measuring social capital, there is no clear and reliable way to measure it in all countries and at all times. The easy way to measure social capital is through questionnaires as developed by the World Bank. This questionnaire or these questions are subject to correction and modification according to the place, time and culture of the study, as they are. They are also subject to translation into the languages of the country to be measured for social capital, and these indicators are the groups and networks index, the trust and solidarity index, the collective action and cooperation index, the information and communication exchange index, the social cohesion and inclusion index, the index, power participation and political action.

1- Al-Hourani (2009)

This study sought to develop a measure of online social capital in Jordanian society, and to indicate the content of interconnected and bridging social capital among internet users. 281) users of the Internet in Internet cafes on University Street in Irbid and registered in the Guinness Book of Records. The global analysis was applied to the paragraphs of the original scale (51 items) and considered the saturation level $(0.500)$ or more as a criterion for 
calculating the paragraphs. The result was that (31) paragraphs were saturated. Of which (paragraph 13) is for the sub-correlation scale, and (18 items) for the bridging sub-scale, and the factor analysis using the basic components method revealed (10 factors. As for the reliability of the scale, it was using Crownbach Alpha, and its value was (0.9). The internal consistency of the paragraphs The study showed the existence of a bridging and interdependent social capital among Internet users, and no statistically significant differences were found due to the variables of sex, place of residence, educational level, work status, religion, age, or monthly income of family.

Nan Lin - Nan Lin, (1999)

This study was concerned with exploring the nature of capital and the different theories of capital, so that social capital can be properly perceived and located. Then, identify some of the controversies that, unless clarified or resolved, will hinder the development of social capital theory. By looking at social capital as assets in networks, this paper discusses some of the issues in concepts, measures, and causal mechanisms (factors that lead to inequality in social capital and the subsequent returns to investments in social capital). The paper concluded by drawing attention to the emergence of a new form of social capital, and electronic networks, which is virtual capital.

Here social capital is addressed as a theory of action and construction.

Studies that dealt with social capital and its relationship with the clan and civil society organizations:

\section{Hala Bensasi (2014)}

This study was concerned with talking about many internal and external challenges, which undermined the degree of its effectiveness in contributing to the development of the environment in which it interacted, in addition to the method followed by the state in dealing with these activities, where does it work to eliminate its material foundations and contain them in the service of its interests, the matter. Which leads to a weakening of its role and effectiveness. In addition, the vast expansion of the state's role in all fields contributed to the inability of civil society to perform its suggestive function between society and the state, which led to weak channels of participation, cultural and accountability, and the spread of corruption and social, economic and political problems, which explains the inability of the local administration In translating the demands and pressures directed by society into successful public policies due to the lack of activation of channels of participation and the absence of communication between the political group and civil society, this is what prompted the participation of civil society organizations in managing local affairs in order to support the local development path, and thus encourage the citizen to adopt Subordinate policies based on ideas he contributed to crystallizing, and this leads to the progress towards consolidating democracy, political participation and public freedoms, respect for human rights and pluralism, and thus civil society becomes an important mechanism to achieve the desired effectiveness. That despite the role played by civil society organizations, but in many developing countries there remains a formal role that has not yet reached the essence of reform and rationalization, and this is for many reasons, including what is directly related to these organizations, such as the lack of clarity of the work programs of these organizations and the modest work experience, Or even the absence of creativity and economics on certain activities, or it is related to the environment of these organizations that does not help them in crystallizing their ideas and realizing them in reality, in addition to the material obstacles, bureaucracies and management pressures, and the level of development of most of these organizations is weak due to the absence of the characteristics of civil society, which led to the absence Most of the foundations and pillars of civil society in it, which is the absence that facilitates its collapse in front of the first obstacles that it faces, and consequently the loss of all the elements of confidence, influence and attractiveness of the local community groups, thus losing a large part of the credibility and the ability to perform their functions. However, despite the fragility of these organizations and their minimal impact on the local development process, their presence is necessary as they reflect the existence of a civil society in a state of crystallization and reflect many values in the path of democracy, such as freedom of association, opposition, diversity and expression, not to mention that the time required for society to develop What exists is much less than the creation of what is not.

This study adopted the qualitative approach to examine the decision-making processes of undocumented male Mexican immigrants about the destination, which illustrated how the interaction between social networks, social capital, and individual circumstances affects American destination choices, both when immigrating from Mexico and when moving within the United States. Based on seventy semi-structured in-depth interviews with undocumented Mexican immigrants primarily residing in Colorado, the study findings illustrate the importance of geographic diversity of social ties, type of migration (international versus internal), type and strength of ties, and the form of interpersonal interactions with ties, For the results of the respondents' destination.

Malin Arvidson, Håkan Johansson \& Roberto Scaramuzzino (2018)

The main functions of civil society organizations are to criticize and hold governments to account. Recent trends in privatization and contracting challenge opportunities for civil society organizations to express such criticism. The purpose of this article is to analyze whether and why civil society organizations are "backing away from their criticism" of public authorities, and how advocacy at risk can be linked to financial, organizational, and institutional factors. The article is based on an original survey of 2,678 Swedish civil society organizations. 
Analyzes show that certain levels of funding make civil society organizations more likely to back down from their criticism, but organizational and institutional factors also play a role. The results determine the importance of distinguishing between objective and subjective factors regarding how dependency is framed. It is the needs, experiences and perceptions felt by civil society organizations themselves that make them vulnerable to the strategic choice of curbing criticism of public authorities.

Bin Jamaan (2015)

This study examines the role of civil society organizations in the development of local communities, and the study aimed to identify the current situation of these organizations and NGOs and their strengths and weaknesses, to highlight their role in society, and what are the necessary interventions to revive the role of these organizations and associations, and this study used the social survey method The sample was based on direct observation, questionnaire, and personal interviews. The study sample consisted of (7) organizations, associations and civil society institutions. The most prominent results of the study: There is a gap between some associations and civil society, and there are associations and organizations that were mainly established for specific purposes in response to specific development programs, and then those societies stopped, and the presence of previous development experiences that did not succeed, due to their failure to be subjected to evaluation and study before starting those activities, and lack of understanding Due to the nature and traditions of those local communities, these programs and activities were subject to failure.

-3 Al-Kafarneh, Maysara Mahmoud, (2015)

This study came to know the impact of NGOs in Palestine by focusing on the Union of Agricultural Work Committees in the Gaza Strip, their role in building social capital, and their role in achieving gender-based development when building social capital, and the descriptive and analytical approach was used for the study. This study concluded that social capital contributes significantly to the interest in the cooperative dimension and the participation of community groups in setting priorities and monitoring their implementation.

-4 Al-Hourani (2012)

The study focused on revealing whether the tribe represents a social capital for the members of the tribes in the Jordanian society, by measuring the interest components on which loyalty to the clan is based, and the returns it provides to individuals, and then measuring the most prominent transformations that tribal loyalty has undergone. Emphasis was placed on five components of tribal loyalty: emotional support, access to scarce resources, the ability to mobilize solidarity, networking with the clan, and the homogenous reference. The sample of the study included (3032) males in northern Jordan (Irbid, Mafraq, Ajloun, and Jerash). The results showed that the clan represents a social capital, and that tribal loyalty remains strong, and through it individuals achieve (emotional support) represented by reassurance, existential security, self-esteem and confidence. Individuals also achieve (access to scarce resources). Such as getting money, work, position, vertical mobility, and social power. And access to decision makers. as such Individuals achieve according to their loyalty to the clan (reference homogeneous) and are embodied by relational balance, intellectual consistency, and joint agreements. In addition, individuals possess according to their loyalty to the clan (the ability to mobilize solidarity) whereby their loyalty can mobilize their relatives to address certain situations, or in the event of a specific emergency, or to carry out important work. And individuals acquire through

Their loyalty (networking with the clan), which gives them membership and identity, and therefore they are obligated to attend clan meetings, keep visiting relatives, and are in solidarity with their clan in all situations and occasions. The results indicated that all members of the sample from all economic levels have strong loyalty to the clan, regardless of their marital status, and their work status as well. It was also found that the elderly are more loyal than the city's residents, and that the educated are distinguished more than the educated, even though all of them have strong loyalty to the clan.

Studies that have linked social capital to sustainable development

-1Iman Bahi (2019)

The 2030 Sustainable Development Agenda, which was adopted in September 2015 as the international path of development, emphasizes the importance of the role of civil society in achieving the sustainable development goals. It also affirms its commitment to partnering with civil society organizations in achieving these goals. Goal 17 of the Sustainable Development Goals emphasizes the importance of a global partnership for sustainable development. He also called for building partnerships with relevant stakeholders, as the partnership between the parties to the development process helps in gathering knowledge, expertise and financial resources in order to achieve sustainable development in its three dimensions, economic, social and environmental. Goal 17 of the Sustainable Development Goals called for encouraging and strengthening partnerships between the public, private and civil society sectors in order to benefit from the experiences gained and resource mobilization strategies. The importance of civil society is embodied in its organizations that can make a real contribution to sustainable development if they succeed in building development awareness, stability and employment through real and effective participation in the development process. This importance has increased in recent decades as a result of economic, social and political changes. The retreat of the state's role and the expansion of the market's forces 
showed the importance of a rights-defending party represented in civil society. The goal of strengthening the partnership with civil society requires enabling civil society to operate effectively within an enabling environment that includes legal frameworks for the work of civil society organizations, their right to obtain information and the necessary resources, and their ability to participate in policy-making. This partnership shall have responsibilities such as follow-up, disclosure, accountability and mutual accountability.

-2Habagi. (2016)

The researcher focused on studying the concept of social capital in the context of stressing the need to benefit from informal ties and relationships in sustainable development, especially in developing countries, in which the basic mechanisms are represented by which the poor depend on adapting to economic deprivation.

And that is through activating the role of non-governmental organizations, and thus social capital is the way to achieve sustainable development in those countries, because the more manifestations of social capital, the greater the confidence, and the researcher relied on the sample survey method through descriptive study, and the questionnaire was distributed to a sample It consists of 300 beneficiaries, volunteers, and workers in the administrative apparatus of NGOs in Port Said.

\section{Nancy Stevenson (2016)}

This study was concerned with participating in local festivals and the effects this has on the social sustainability of a destination. Two case studies were developed from a research project looking at local festivals held in the Hackney Wake and Fish Island area adjacent to Queen Elizabeth Olympic Park in East London, UK between 2008 and 2014. London 2012 looks like the London 2012 Olympic Games. The two Todan festivals here respond to challenges. And opportunities for growth and presence in the region. The title is a festival to foster a sense of community

By creating an experience and improving communication across diverse groups. The other brings the cultural community together and connects them to the opportunities that arise when the region emerges as a destination 5.1.4. These festivals increase social capital in the region, but their distribution is highly uneven. Social capital exacerbates existing inequalities within a society

Host, for the benefit of the "haves" over the "haves not". There are tensions between social capital development and social sustainability in this emerging start.

\section{Edward O'Boyle 2011}

This article is about Stanfield's interests in social capital, sustainable development, and the sponsorship we refer to as patronage. We also address many other virtues, including compassion, benevolence, and generosity, which have been part of the economics literature since the time of Smith's moral sentiments along with the vices of heartlessness and impiety.

Sensitivity, meanness, greed, and others. This article attempts to show that the addition of social capital to the machine-like individual in mainstream economics results in a person's representation of the personal economy which becomes a fully human person through social interactions that promote the development of many virtues or a human being through other interactions that inculcate certain vices; And that, in matters related to sustainability, becoming a human being fully calls for practicing the virtues of justice and moderation in particular. In addition, we have proposed a framework for thinking about sustainable development in terms of operationalizing and limiting principles and developing critical values or performance standards for people-centered sustainable development.

\section{Yvonne Rydin \& Nancy Holman, 2004}

This study focused on presenting the concepts of social capital. By making a wide range of claims for the analytical potential of social capital, some have led some to question the concept's continuing value. The researcher found that the concept still has great value if used in a rigorous and accurate manner. And that the concept has special value when considering sustainable development policy. However, just as sustainable development is a multifaceted concept, this application requires a multifaceted reading of social capital. He finds that a clearer classification of social capital is needed, and has proposed a three-dimensional classification, adding a new class of "support" social capital to the more common distinction between "connectedness" and capital.

Social "bridges." We also address the issues of what social capital can do and how it actually works, specifically in the context of sustainable development policy.

Commentary on previous studies

Previous studies, both ancient and modern, that deal with the subject of social capital, regardless of its real or hypothetical characteristics, have shown, and although this social concept appeared in Europe initially, interest in it came in various parts of the world,

Eastern and Western societies, socialism and capitalism, with different groups and segments such as students, the elderly, immigrants, capital owners, and low-income people, and this indicates the importance of this concept, 
within different societies, and within different stages of time, and different ideological trends.

It has been evident that the social network leaves a clear impact on most aspects of social, political and economic life. How can this effect be achieved through social capital in achieving sustainable development by dealing with different dimensions of social capital such as the clan and civil society organizations in the Jordanian society at a stage.

The states strive for civilization and modernity, where the clan represents the traditional form and the mechanical interdependence of groups, and civil society organizations represent the civil form, the organic solidarity of groups.

\section{Theoretical framework}

Theories that discuss the role of social capital

Individuals 'social capital is formed through various social systems that are linked to the social networks of these individuals and groups to which they belong, whether these groups were born in them and belong to them through kinship and blood ties, or joining them through the position they occupy by joining professional unions, Or even through social spaces where they congregate to express their opinions and attitudes.

The concept of social capital was first used by Hanifan in 1916. Sociologist Pierre Bourdieu (2016) and despite the origin of the term social capital dating back to the nineteenth century, the development of this concept has been associated with three main academics, namely James Coleman, Pierre Bourdieu and Robert Putnam, and in the last two decades it has adopted International bodies for the term social capital and its role in productivity and confidence enhancement (Al-Arabi, 2018)

Coleman uses the concept of social capital to refer to an area that others have rarely noticed, which is the relationships that exist between individuals in the family and community frameworks. It is believed that the relationships within the family exert a strong influence on the educational attainment levels of their children, as the mother believes that there are two types of social relations networks that are closed within small groups, and open or weak that arise from the absence of interaction between parents and their children, and between parents and the rest of adults in the community of Other side (Abdel-Azim, 2012).

It may appear here that Coleman was interested in social capital emerging in small groups and the family, and this may apply to the network of social relations emerging in the clan, although the number of some large clans in Jordanian society may reach hundreds of thousands.

While "Putnam" mentions that social capital is "a group whose members are trustworthy and who place great trust in each other will be more capable of achievement compared to other groups that lack confidence among its members."

Putnam developed the concept of social capital, and although he was not the first to introduce this concept, he was the owner of the largest share in the development and analysis of the concept.

Putnam's concept of social capital refers to "features of social organization, such as networks, norms and trust, which facilitate coordination and cooperation to achieve mutual benefit." Social capital enhances the benefits of investing in both physical and human capital. It is a social term that denotes the value and effectiveness of social relations and the role of cooperation and trust in achieving economic goals. In a general sense, social capital is the main pillar of social relations and consists of the sum of the benefits that can be achieved through cooperation between individuals and groups of a society and the differential dealing with it.

As Putnam.R explained, when people meet and spend time together they develop relationships that create trust and cohesion. This is called social capital, and here it is a reason to drive economic development. Putnam provided a good explanation for the potential of the social capital component to support Good government and economic progress

By building civic engagement networks underpinning strong rules of reciprocity. In general: I will do this for you now, with the expectation that you will help another person or do the same to me when needed, in accordance with the principle of (giving back), or what has been called a "charity bank". Putnam, 1993)

In his view, it is important that social capital be self-reinforcing and accumulating. This means that successful cooperation in one endeavor builds relationships and trust, the social assets that facilitate future cooperation in other tasks, and civic engagement networks facilitate coordination, communication, and information amplification between individuals, which reduces the motivations of opportunism and misbehavior.

Putnam stressed that social capital is one of the most important factors in achieving economic development. Studies conducted on the fast-growing economies in East Asia have always emphasized the importance of dense social networks. They also presented a new concept in this field, which he called "network capitalism." Capitalism: It is a brand new one

It is based on complex families or highly interconnected ethnic communities that enhance trust and cooperation, reduce financial transactions, speed the transfer of information and innovation. (Putnam 2003).

He also indicated the possibility of converting social capital into financial capital, as has already happened in the experience of economic growth in China during recent decades, as reliance on social networks / influence (personal relationships) to support contracts and direct savings and investment was greater compared to reliance 
on institutions. Official.

In other non-Asian models, the emphasis on the element of social capital was present. It was mentioned, for example, in the proposals of US President Bill Clinton on economic development plans, job training and industrial extension agencies. He shed light on the concept of social capital, saying: "It should not be Total reliance on technical expertise

And work skills only, but new and fruitful links must be created between different parts of society, schools, employers and workers, without creating costly new bureaucratic systems "(Putna, 2003).

Negatives to social capital according to Putnam

When we talk about the positives of social capital and the realization of many social, political and economic advantages, a justifiable question arises: Can social capital have a negative impact on society, just like human and material capital, social capital can be used for negative purposes. Chief among them is the entrenchment of social inequality as part of social capital, as norms and networks serving some groups can hinder other groups (Putna, 2003).

This may affect the achievement of a comprehensive, sustainable and equitable development for all segments of society, so that certain groups benefit, while other groups are deprived of benefiting from the positives of sustainable development in any society.

Pictures of social capital in Jordan

Every society is characterized by a set of norms, customs and social values, which contribute to the nature of forming a network of social relations, and Jordan as a modern country enjoys the existence of civil institutions such as civil society organizations, while traditional forms of groups such as clans that extend a history before the establishment of the modern Jordanian state are rooted in it. The premise that the components of social capital appear in the Jordanian society, specifically in the city of Amman, and are represented by:

Clans

The clan is an essential component of Jordanian society and has an important and pivotal role in the process of building the modern Jordanian state, and some consider it one of the most important causes of stability and moderation, not only on the social level, but also on the political level.

Despite the diversity of the ethnic origins of these clans, the emergence of modernity and postmodern trends in the world now, and the shedding of light on the concept of individualism, the clan is still a social institution through which individuals form a network of social relations in Jordanian society.

In (Al-Hourani study 2012) the results show that technological progress. And the capitalist tendency, and the relative tendency to individualism, and others. All of them weakened the formal cohesion of the clan structure, but did not nullify the fundamental cohesion of loyalty to the clan. While tribal loyalty used to express a legitimate historical situation and fulfill important social and political functions such as securing protection, security, and identity, it is considered at the present time an indication that contemporary political and social structures have not crystallized in an integrated manner.

The Arab Human Development Reports, most of the World Bank and IMF reports showed that traditional tribal identity and tribal loyalty is considered an obstacle to structural economic, political, and institutional reform and reliability of the system (AHDR: 2003.(

This is given that tribal loyalty restricts the development of societies and the orientation towards modernity, but we cannot benefit from this large network of relationships?

Any network of relationships based on ethnicity or kinship is a form of social capital, and although Putnam considered that one of the drawbacks is that some groups have privileges for their members without others, but since most members of Jordanian society belong to clans, and trust them to a high degree Then, it can take advantage of that network of social relationships

It is known in the Jordanian society that the tribes have a clear role in the political process, especially the parliamentary and economic, so how can they not have that role in achieving sustainable development, since they represent an important form of social relations network, although there are negatives facing the achievement of these goals, such as prejudice Sometimes for the group, or preferring the participation of members of one clan, over the members of other clans, but it is possible

These negatives are avoided by setting specific standards for ways to contribute to sustainable development, especially since the sustainable development goals are continuous for future generations, and do not depend only on the present moment.

\section{Civil society organizations}

Civil society organizations consist of bodies called secondary institutions such as civil societies, professional and labor unions, business companies, chambers of commerce and industry, charitable institutions, civil societies, volunteer bodies, human rights societies, women's rights associations, sports clubs, consumer protection societies, etc. Similar from the voluntary institutions. What is meant is that the scope of civil society is limited to institutions and non-governmental organizations whose activities are based on volunteer work, and hence it is a society largely 
independent of direct state supervision (Bouchanger 2014)

Civil society organizations play a fundamental role in achieving environmental as well as sustainable development, and these roles lie in engaging civil society institutions in setting development plans.

There is a large number of organizations that provide various services in the city of Amman, and all over the Jordanian state. A directory of civil society organizations has been established in Jordan aimed at introducing these organizations, their vision and goals to citizens, and their establishment came in cooperation between the Phoenix Center for Economic and Informatics Studies and the Friedrich Ebert Foundation.

This encyclopedia includes various Jordanian civil society organizations as well as Arab and foreign community organizations operating in Jordan. Civil society organizations were classified according to their goals and fields of work, which included employers' unions and associations.

And chambers of commerce and industry, trade unions, professional associations, trade unions, disability care organizations, environmental, cultural and scientific organizations, youth and sports clubs, health care organizations, child care organizations, orphans and women, multi-purpose charities, in addition to organizations working in the fields of development, community protection and human rights (economic and informational studies, Al-Feng).

The role of civil society and its institutions cannot be overlooked in pushing countries to conclude many international agreements related to sustainable development, preserving the environment, achieving justice and equality, combating poverty and gender, as participation is the basis of work within these institutions, and the concept of comprehensive development includes the concept of coordination Environmental and the concept of continuous development and human development. The absence of participation is considered one of the most important factors in the failure of development in all its aspects and its non-continuation. Therefore, the role of social networks in contributing to increasing and activating this participation cannot be overlooked, just as it is not possible to overlook their role in public oversight in achieving goals. sustainable development.

\section{Civil society organizations}

Civil society organizations consist of bodies called secondary institutions such as civil societies, professional and labor unions, business companies, chambers of commerce and industry, charitable institutions, civil societies, volunteer bodies, human rights societies, women's rights associations, sports clubs, consumer protection societies, etc. Similar from the voluntary institutions. What is meant is that the scope of civil society is limited to institutions and non-governmental organizations whose activities are based on volunteer work, and hence it is a society largely independent of direct state supervision (Bouchanger 2014)

Civil society organizations play a fundamental role in achieving environmental as well as sustainable development, and these roles lie in engaging civil society institutions in setting development plans.

There is a large number of organizations that provide various services in the city of Amman, and all over the Jordanian state. A directory of civil society organizations has been established in Jordan aimed at introducing these organizations, their vision and goals to citizens, and their establishment came in cooperation between the Phoenix Center for Economic and Informatics Studies and the Friedrich Ebert Foundation.

This encyclopedia includes various Jordanian civil society organizations as well as Arab and foreign community organizations operating in Jordan. Civil society organizations were classified according to their goals and fields of work, which included employers' unions and associations.

And chambers of commerce and industry, trade unions, professional associations, trade unions, disability care organizations, environmental, cultural and scientific organizations, youth and sports clubs, health care organizations, child care organizations, orphans and women, multi-purpose charities, in addition to organizations working in the fields of development, community protection and human rights (economic and informational studies, Al-Feng).

The role of civil society and its institutions cannot be overlooked in pushing countries to conclude many international agreements related to sustainable development, preserving the environment, achieving justice and equality, combating poverty and gender, as participation is the basis of work within these institutions, and the concept of comprehensive development includes the concept of coordination Environmental and the concept of continuous development and human development. The absence of participation is considered one of the most important factors in the failure of development in all its aspects and its non-continuation. Therefore, the role of social networks in contributing to increasing and activating this participation cannot be overlooked, just as it is not possible to overlook their role in public oversight in achieving goals. sustainable development.

When reviewing the goals of sustainable development, it is easy to feel the importance of the role of social capital in achieving these goals. The human element is the main goal in this development, whether in the current era or in the future, and the human element is the main actor in achieving these goals. These individuals and how they affect the achievement of these goals is central to achieving sustainable development.

Social capital, represented by all forms of the network of relationships existing in the Jordanian society, is the best and most appropriate option for achieving this development. Social capital is not a single entity, but rather 
consists of a set of dimensions that are difficult to measure, such as trust, information exchange, loyalty, community engagement, political participation and empowerment. We can always benefit from community institutions and groups within society that form a network of social relations side by side to achieve economic, political and social goals that serve all segments of society. It is not necessary to replace the clans with civil society organizations, and to cancel the cultural and anthropological history of groups to achieve the trends of modernity. These social institutions have important social roles, and taking advantage of them together achieves greater goals and contributes to activating social capital that achieves sustainable benefits for the entire society.

Sustainable development has clear goals and it is a positive process, but this does not prevent the existence of negative side dimensions to it, as the process of sustainable development in some of its aspects may require the complete dispensing of energy that provides people with the requirements of modern life, and the modification of the infrastructure, and this shift in consumption patterns will cost Excessive sums and burdens; Specifically for developing countries.

Like unemployment, the requirements for sustainable development are the protection of ecosystems and biodiversity, and this can only be achieved by reducing or even stopping many industries and their activities, and this in turn leads to the spread of unemployment, especially among individuals who have devoted their lives to work in one sector, and here comes the role of the network of social relations Which supports individuals in these situations, and participates with them in finding solutions that contribute to mitigating or eliminating these negatives, as social capital is collective ownership.

Development takes a deeper dimension at the individual level; Because in the end it is an investment in people, especially women and the family. If we invest in them and develop them from the social, cognitive and economic side, then we will have created a cohesive society.

It takes another essential dimension, as sustainable development is an appeal to the achievement of maximum human well-being. Terry Anderson, Laura E. Huggins (2004

\section{Research Methodology}

This study relied on the descriptive and analytical approach, as previous studies that dealt with the topic of social capital were referred to in terms of studies that dealt with its concept, and previous studies that dealt with forms of social capital represented by the thorny and civil society organizations, and previous studies that linked capital were reviewed. Social and sustainable development, and analyzing the results of these studies and linking them to the aspects of social capital in the city of Amman represented by the clan and civil society organizations, and how the role of social capital can be activated in achieving sustainable development in the city of Amman, in a way that suits the specificity of this city within the Jordanian society.

\section{Conclusion and results}

Many previous studies have shown that a network of social relations is linked to achieving economic and political goals, which indicates the importance of the role of social capital in achieving sustainable development. The aspects of social capital in Amman are represented by civil society organizations and clans, whose roles appear in the parliamentary and municipal elections. And access to job opportunities, or participation in economic investments, and since they are effective and leave an impact in the political and economic sphere, it is therefore important to work to activate their role in achieving sustainable development.

Putnam has proposed the possibility of permanence in social capital, but the reality shows that in many cases, social capital is subject to erosion and recession, and is not always renewed and sustainable, or until its shape changes, so now, for example, we are talking in the current era about virtual social capital through websites. Social Media.

But social capital does not depend on people, but rather on the nature of the network of relationships, and how it can be benefited from. Unlike traditional capital, it is not a private property, but a public benefit that serves the entire community. Therefore, it is important to study the development of forms through technological development and intellectual trends, and to resist its decline. With the increase in individualism in the world, and interest in analyzing the role of countries in increasing opportunities for social communication.

Many internal and external challenges, plague civil society organizations, may limit their role, which leads to weakening their role and effectiveness. In addition, the vast expansion of the state's role in all fields has contributed to the inability of civil society to perform its function between society and the state, and this may reduce the confidence of individuals in it, and this may lose part of the advantages as social capital in the Jordanian society.

While the clan is considered biased towards its members despite its high confidence and loyalty on the part of its members, and since these two forms of groups constitute the social capital in the city of Amman, one of them cannot be ignored with the aim of modernity and civility, nor can they rely on one without the other to achieve social justice for all members of society. 


\section{Recommendations}

1. Interest in studying ways of developing forms of social capital in Jordanian society.

2. The clan forms a network of social relations characterized by trust, loyalty and networking, while civil society organizations form a social network that is characterized by contributing to political empowerment and civic participation. None of the components of social capital in the Jordanian society should be neglected.

3. The involvement of civil society organizations and the clan plays a fundamental role in developing plans to achieve sustainable development.

4. The necessity of seeking assistance from civil society organizations that have advanced experience in the field of sustainable development.

5. The necessity of involving the clan within its network of relations in achieving the goals of sustainable development

6. Creating mechanisms for communication and coordination between government institutions, civil society organizations and clans to achieve sustainable development goals.

7. Creating communication mechanisms between international and local organizations that represent civil society to achieve greater cooperation and exchange of experiences

8. Achieving an effective sustainable development that is concerned with the three dimensions (economic, social, and environmental), which ensures that the needs of current generations are met without prejudice to the requirements of future generations.

\section{Sources and references:}

Arabic references:

Abu Zaher, Nadia (2008). Social capital and the debate over its relationship with civil society. Civilized dialogue. Issue 2242, Civil Society Center.

Abu Zaher, Nadia (2013). The role of the Palestinian political elite in the formation of social capital, Doha: The Arab Center for Research and Policy Studies.

Sari, Helmy (2016), Social Media, Oman: House of Knowledge and Distribution Treasures.

Al-Hourani, Muhammad Abdul-Karim. 2012. The clan is a social capital: a sociological study of the components of tribal loyalty and its transformations in Jordanian society. Jordanian Journal of Social Sciences, M. 5, p. 2, p. P. $172-$

Al-Hourani, Muhammad. 2009. Developing a measure of online social capital in Jordanian society. Journal of the Union of Arab Universities for Literature, MG. 6, p. 2, p. P. 409-444.

- Ali, Rania Fathy Habagy. (2016), The role of social capital in achieving sustainable development: a study of the role of non-governmental organizations in developing the social capital for the development of Port Said, Ain Shams University - Faculty of Arts

Dr. Al-Arabi Harran, University of Ammar Thleiji Laghouat - Algeria Dr. Al-Tunisi Faeza, University of Ammar Thleiji Laghouat - Algeria

Journal of Social Sciences: 7th Issue December - December "2018", which is an international refereed journal issued by the Arab Democratic Center, Germany-Berlin. It is concerned with publishing studies and research in the field of social sciences in Arabic, English and French.

- Al-Kafarneh, Maysara Mahmoud, (2015), The Role of NGOs in Building Social Capital in the State of Palestine: An Empirical Study: The Union of Agricultural Work Committees in the Gaza Strip (2001-2014)

- Bushanqir Eman - Raqami Muhammad (2014), The Role of Civil Society in Achieving Sustainable Development / Article published in the second issue of The Human Rights Generation Journal, pg. 31

- Belhanafy, Amina (2017), The problem of social capital between concept and measurement, Al-Hikma Journal for Economic Studies

- Mohammed bin Salman, bin Jamaan, 2015, The Role of Civil Society Organizations in the Development of Local Communities: A Field Survey Study on a Sample of Urban Community Development Organizations in Hadramout Governorate Journal Alandalus for Humanities and Social Sciences 2015 Vol.9 Issue 5, pp. 171-212

- Hala Bensassi (2014) Civil Society as a Mechanism for Achieving Local Development, University of Al-Masila Law and Political Sciences and Political Sciences, an unpublished master's thesis.

Abdel-Azim, Hosni, (2012), Social Capital, Civilized Dialogue, No. (3871).

$$
\text { المراجع الانجليزية : }
$$

- Christina A. Sue,Fernando Riosmena \&Joshua LePree(2018), The influence of social networks, social capital, and the ethnic community on the U.S. destination choices of Mexican migrant men, Research site and methodology.

- Nan Lin (1999), Building a Network Theory of Social Capital, Dept. of Sociology, Duke University.

- TANG1,(2018), Social Capital, Sense of Virtual Community, and

Network Group Behavior: An Empirical Study based on Virtual Community Users, REVISTA DE 
CERCETARE SI INTERVENTIE SOCIALA

- Edward O’Boyle 2011, The Acting Person: Social Capital and Sustainable Development, Published online: 23 Dec 2011

- Turner, 2006, Pensions, Risks, and Capital Markets, the Journal of Risk and insurance.

- Robert D. Putnam. "The Prosperous Community: Social Capital and Public Life". The American Prospect (13), 1993. PP 35-42.

- $\quad$ Robert D. Putnam, Better Together: Restoring the American Community, Simon Schuster, 2003.

- Yvonne Rydin \& Nancy Holman, 2007, Re-evaluating the Contribution of Social Capital in Achieving Sustainable Development, The International Journal of Justice and Sustainability Volume 9, 2004 - Issue 2.

- $\quad$ Nancy Stevenson (2016), Local festivals, social capital and sustainable destination development: experiences in East London, Journal of Sustainable Tourism Volume 24, 2016 - Issue 7

- Malin Arvidson, Håkan Johansson \& Roberto Scaramuzzino(2018) Advocacy Compromised: How Financial, Organizational and Institutional Factors Shape Advocacy Strategies of Civil Society Organizations), nternational Journal of Voluntary and Nonprofit Organizations volume 29, pages844-856(2018)Cite this article

websites

Website for Economic and Informatics Studies - Al Feniq http://www.civilsociety-jo.net/ar/home

"ADVANTAGES AND DISADVANTAGES OF SUSTAINABLE DEVELOPMENT"- www.lorecentral.org Retrieved 2019-04-12. Edited.

Terry Anderson, Laura E. Huggins (2004-11-17), "Economic Growth—-the Essence of Sustainable Development" ، www.hoover.org, Retrieved 2019-04-12. Edi

Jordan Department of Statistics http://dosweb.dos.gov.jo/ar/sdgs /

United Nations Development in the Arab countrieshttps://www.arabstates.undp.org/content/rbas/ar/home/sustainable-development-goals.html 